\title{
Soil fertility decline at the base of rural poverty in sub-Saharan Africa
}

To the Editor - Pedro Sanchez ${ }^{1}$ sketched a very optimistic picture for the future of food production in sub-Saharan Africa, and rightfully so. However, he did not stress the need to care for soils, many of which are degraded in this part of the world. This omission of soil management is unfortunate, but far from exceptional; hence, the declaration of 2015 as the International Year of Soils. Here, we outline the importance of soils for the alleviation of poverty in subSaharan Africa.

Traditionally, fields have been left fallow for a number of years, so that the natural vegetation can regrow and soil fertility can be restored. But with increasing population densities and associated demands for land, the practice of leaving land fallow is no longer an option in many areas of subSaharan Africa. As a result, soil degradation processes have intensified. Soil nutrient mining is the most common form of soil degradation, and results in less crop productivity, less biomass and less soil cover, thereby exacerbating other soil degradation processes, such as erosion, acidification and the formation of hard pans (dense soil layers that are largely impervious to water infiltration and root growth). Soil degradation thus reinforces itself, leading to an increasingly complex set of constraints to crop productivity. Ultimately, soils become nonresponsive and plants growing on such soils are no longer able to capture nutrients applied, for instance in the form of commonly available fertilizers.

Low soil fertility is directly linked to low productivity, food insecurity and rural poverty. Food insecurity and poverty, in turn, can cause rural-to-urban migration, increased food importation bills (which compete with investment in agricultural development), and an increased reliance of rural communities on remittances sent from family members living in towns or abroad. Hence, we stress the immediate need to reverse soil degradation before it becomes unachievable and many African smallholder farmers become locked in a poverty trap.

Nutrient imbalances can be remedied relatively quickly through the application of fertilizer or other sources of nutrients. Recently published data show average fertilizer nutrient application rates of 64, 56, 25, 8, 2 and $1 \mathrm{~kg} \mathrm{ha}^{-1}$ for Nigeria, Malawi, Ethiopia, Tanzania, Niger and Uganda, respectively ${ }^{2}$. Independent FAO data ${ }^{3}$ show increases in maize productivity between 2000 and 2013 of 39, 93, 120, 27, 12 and $84 \mathrm{~kg}$ year $^{-1}$, respectively, suggesting larger increases in maize productivity in countries where more fertilizer is used. However, nutrient application should be targeted to responsive soils, and coupled to additional measures designed to improve soil health, and ultimately yield, including the use of improved germplasm and available organic inputs ${ }^{4}$.

In cases where nutrient mining has given way to more complex constraints, longer-term soil rehabilitation measures are needed. Such measures include subsoil tillage to remove hard pans, the application of large quantities of high quality manure to alleviate soil chemistry constraints such as cation imbalances, or the application of lime to eliminate aluminium-related constraints. Soil rehabilitation can restore degraded soils, rendering them responsive to fertilizer addition $^{5}$, but may require incentives because of the limited financial means of most smallholder families.

Commitment to maintaining and restoring the soil resource in sub-Saharan Africa can be fostered by ensuring that farmers have access to affordable agroinputs, and by ensuring that the institutional environment - such as access to credit, appropriate rural infrastructure and profitable output markets - allows farmers to gain an income from their produce and re-invest in soil health. As Sanchez ${ }^{1}$ pointed out, many interventions are needed along the whole food value chain, but we cannot forget that agricultural development starts with a healthy soil producing a healthy crop.

References

1. Sanchez, P. A. Nature plants 1, 14014 (2015).

2. Sheahan, M. \& Barrett, C. B. Understanding the Agricultural Input Landscape in Sub-Saharan Africa: Recent Plot, Household, and Community-Level Evidence (World Bank, 2014).

3. FAOSTAT (FAO, accessed 9 April 2015); http://faostat3.fao.org/ download/R/RF/E

4. Vanlauwe, B. A. et al. Outlook Agr. 39, 17-24 (2010).

5. Vanlauwe, B. A. et al. SOIL 1, 491-508 (2015).

B. Vanlauwe', J. Six², N. Sanginga ${ }^{3}$,

A. A. Adesina ${ }^{4}$

${ }^{1}$ International Institute of Tropical Agriculture,

PO Box 00100-30772, Nairobi, Kenya.

${ }^{2}$ Department of Environmental Systems

Science, ETH-Zurich, 8092 Zurich, Switzerland.

${ }^{3}$ International Institute of Tropical Agriculture,

Oyo Road, PMB 5320, Ibadan, Nigeria.

${ }^{4}$ African Development Bank, Immeuble du

Centre de Commercie International d'Abijan,

Avenue Jean-Paul II, 01 BP 1387, Abidjan 01,

Côte d'Ivoire.

e-mail: b.vanlauwe@cgiar.org; jsix@ethz.ch;

n.sanginga@cgiar.org; adesina1234@gmail.com 